\title{
A Gender Perspective of Addictive Disorders
}

\author{
Francina Fonseca $^{1,2,3}$ (D) María Robles-Martínez ${ }^{1,2}$ (1) • Judit Tirado-Muñoz ${ }^{1} \cdot$ María Alías-Ferri $^{1,3}$. \\ Joan-Ignasi Mestre-Pintó ${ }^{1,4}$ (I) $\cdot$ Ana Maria Coratu ${ }^{1,2} \cdot$ Marta Torrens $^{1,2,3}$ [D
}

Accepted: 8 January 2021 / Published online: 16 February 2021

(C) The Author(s), under exclusive licence to Springer Nature Switzerland AG part of Springer Nature 2021

\begin{abstract}
Purpose of Review Substance use disorders (SUD) affect differentially women and men. Although the prevalence has been reported higher in men, those women with addictive disorders present a more vulnerable profile and are less likely to enter treatment than men. The aim of this paper is to present an overview of how sex and gender may influence epidemiology, clinical manifestations, social impact, and the neurobiological basis of these differences of women with SUD, based on human research. Recent Findings The differences in prevalence rates between genders are getting narrower; also, women tend to increase the amount of consumption more rapidly than men, showing an accelerated onset of the SUD (telescoping effect). In respect to clinical features, the most important differences are related to the risk of experience psychiatric comorbidity, the exposure to intimate partner violence, and the associated high risks in sexual and reproductive health; and those who are mothers and addicted to substances are at risk of losing the custody of children accumulating more adverse life events. Some of these differences can be based on neurobiological differences: pharmacokinetic response to substances, sensitivity to gonadal hormones, differences in neurobiological systems as glutamate, endocannabinoids, and genetic differences.

Summary Specific research in women who use drugs is very scarce and treatments are not gender-sensitive oriented. For these reasons, it is important to guarantee access to the appropriate treatment of women who use drugs and a need for a gender perspective in the treatment and research of substance use disorders.
\end{abstract}

Keywords Gender · Addictive disorders $\cdot$ Addiction $\cdot$ Sex differences

\section{Introduction}

Substance use disorders (SUD) are complex and chronic diseases influenced by genetic, environmental, and social factors. Women present distinct epidemiology, natural history, course, and response to treatment in SUD. Data from the World Drug Report 2020 [1], remarked that, although overall, the

This article is part of the Topical Collection on Gender

Marta Torrens

mtorrens@parcdesalutmar.cat

1 Addiction Research Group (GRAd), Neuroscience Research Program, Hospital del Mar Medical Research Institute (IMIM), Barcelona, Spain

2 Institut de Neuropsiquiatria i Addiccions, Hospital del Mar, Barcelona, Spain

3 Universitat Autònoma de Barcelona (UAB), Cerdanyola del Vallès, Spain

4 Universitat Pompeu Fabra (UPF), Barcelona, Spain prevalence of SUD is generally lower among women than men, women who do have a SUD appear to be particularly vulnerable; the most important differences are related to the risk of experience higher psychiatric comorbidity; also, they are exposed to intimate partner violence, with high risks in sexual and reproductive health; and those who are mothers and addicted to substances are in risk of lose the custody of children accumulating more adverse life events. Moreover, while one of three drug users is a woman, women continue to account for only one in five or fewer people in treatment [1].

The National Institutes of Health Office of Research on Women's Health defined sex as biological differences between females and males, and gender is defined as socially determined roles that vary across cultures and overtime [2]. The World Health Organization (WHO) definition [3] of gender is the result of socially constructed ideas about the behavior, actions, and roles a particular sex performs. In relation to assessing and treating women's medical issues, a gender perspective is required, transcending anatomical and biological aspects concerning health and sickness through life. Gender has implications for health across the course of a person's life 
in terms of norms, roles, and relations. It influences a person's risk-taking and health-seeking behaviors, exposure to health risks, and vulnerability to diseases. Also, gender influences other sources of possible inequalities as ethnicity, socioeconomic status, disability, age, geographic location, and sexual orientation, and these differences could be related to several factors, such as social stigma, feelings of shame, denial, fear of losing their children, lack of specialized resources, and lower purchasing power $[5,6]$. In general, women through all their lifetime face more barriers to access to services, and this issue is more prominent in addictive disorders; such barriers include the higher stigma attached to substance use among women, the lack of childcare, the absence of gender-sensitive protocols and treatments, and the lack of family support among others. One of the priorities of WHO is to reduce gender inequality and remove barriers to treatment access [4].

One example of a more severe response to stress could be the present coronavirus disease 2019 (COVID-19) pandemic; for instance, many sexual and reproductive health services have been closed as not being considered as essential; this has been translated into less access to contraception methods resulting in more non desired pregnancies and more sexually transmitted illness [7]. Also, the effects of pandemics on women's mental health have been studied; one study performed in Wuhan showed that women presented more post-traumatic stress symptoms in the domains of re-experiencing, negative alterations in cognition and mood, and hyper-arousal [8].

This paper aims to present an overview of how sex and gender may influence epidemiology, clinical manifestations, social impact, and the neurobiological basis of these differences of women with SUD, based on human research.

\section{Epidemiology}

It has always been said that men show higher rates of substance use, abuse, and dependence than women [9-11], but recent epidemiological surveys suggest upcoming changes and differences that might be narrowing this gap. In some types of drugs, their use is more prevalent in women than in men, for example, sedatives and weight loss pills. In other cases, there has been a greater increase in women than in men; this is the case of cocaine use in some countries as Argentina and Bolivia [1]. In the case of alcohol, although men usually use alcohol in larger quantities, drink more frequently, and are more hazardous drinkers, these differences are decreasing in the last years, usually in younger cohorts and with women starting drinking at younger ages $[12,13]$. In the case of prescription and non-prescription opioids, recent trends in the USA found that the use of heroin is increasing faster in women than in men, and the decrease in nonmedical prescription opioid use is slower than in men; also, this study showed differences in the risk for opioid use, being women at higher risk for nonmedical prescription opioid use than for heroin use [14]. In this sense, the initiation in the use of opioids is different also; women are more likely to start with a legal prescription for the treatment of pain than men [15].

Differences in rates of substance use have been usually related more to gender/cultural environment than to sex/ biological factors; the explanation for this ratio difference was that men had more access to substances than women, in most cultures; furthermore, when studies have controlled the variable "access to substances," the probability to use drugs is similar for men and women [16••].

While women who use drugs typically begin using substances later than men, once they have initiated substance use, women tend to increase their rate of consumption of alcohol, cannabis, cocaine, and opioids more rapidly than men. This phenomenon is known as "telescoping," which means an accelerated progression from the initiation of substance use to the development of SUDs and entry into treatment $[17,18]$. This quicker progression from first using the substance to developing dependence may explain that women typically enter SUD treatment with more severe medical, behavioral, psychological, and social problems. However, it is necessary to remark that some studies have not replicated the telescoping effect $[19,20]$. This discrepancy could be related to methodological issues, for instance, this effect has been more clearly described in the population under treatment, maybe indicating that this phenomenon is more relevant in severe subjects.

Differences are seen in the reason for the initiation of drug use. Girls usually started using alcohol and other drugs as coping strategies to face depression, anxiety, and negative feelings [21], whereas men usually initiate the use of drugs influenced by peers or sensation-seeking [22]. The fact that women are more exposed to negative life events such as trauma and intimate partner violence is directly related with the rapid development of substance use and the narrowing gap between rates of drug use among genders [23]. Despite all this, it has been described that women who adhere to specialized treatment achieve better results [24] than men and are also more predisposed to receive information about the treatment process [25].

\section{Ethiopathogenic Mechanisms}

\section{Neurobiological Basis of Sex Differences}

Differences observed between men and women can be based on sex differences: neurobiological differences, from differences in the pharmacokinetic response to the effects and sensitivity to gonadal hormones, and also, genetic differences between men and women [26••]. It is important to remark that the majority of studies that have evaluated these effects have been performed in Europe and North America; genetic and 
ethnic differences could exist, and further research is still needed in this sense.

The development of addictive disorders could be divided into 3 stages: binge/intoxication; withdrawal/negative affect and preoccupation/anticipation phases [27••]. The binge/ intoxication stage is mediated by reward neurotransmitters, like dopamine and endogenous opioids, and involves the neurocircuits of the basal ganglia; the withdrawal/negative affect stage is characterized by common symptoms as sleep disturbances, dysphoria, malaise, and irritability where there is a principal involvement of the brain stress systems in the extended amygdala, mainly corticotropin-releasing factor (CRF) and dynorphin. The preoccupation/anticipation stage (or "craving" stage) is characterized by the dysregulation of executive systems in the prefrontal cortex [28]. Many of these neurotransmitters (dopamine, CRF...) have different regulation and expression between sex in animal models [29].

\section{Pharmacokinetics of Sex Differences}

There have been described sex differences in the physiologic effects of different substances, and their pharmacokinetic properties as well, for instance, blood concentrations of drugs are different for men and women after similar doses [30]. These differences contribute to the different effects and outcomes in substance use disorders for men and women.

Alcohol Women get intoxicated with lower doses of alcohol than men; this difference seems to be related to alcohol pharmacokinetics with a biological basis, being sex-related rather than a gender-related factor. Men and women presented differences in the alcohol metabolism at different stages: some researchers have described differences in first-pass metabolism [28]; a minor total body water content in women, achieving higher blood alcohol concentrations; other reason might be the lower concentration of gastric alcohol dehydrogenase (one enzyme responsible of an important amount of the alcohol metabolism) in women [12••].

Nicotine As the case of alcohol, nicotine plasma concentrations are higher among women than in men and these concentrations are achieved more quickly. This phenomenon is more intense in women taking estrogen contraceptives, but not if they are taking progesterone-based contraceptives [31].

Cocaine In the case of cocaine, peak plasma concentrations differ between men and women, depending on the route of administration. Men achieved higher concentrations through the intranasal route compared to the intravenous route, whereas in women, the plasma concentrations can change depending on the phase of the menstrual cycle, achieving higher concentrations in the follicular phase than in the luteal phase $[32,33]$.

\section{Neuroactive Gonadal Steroid Hormones}

Other factors associated with differences in drug response and sensitivity in women are the effect of sex hormones. Ovarian steroid hormones (estrogen, progesterone), the metabolites of progesterone, and negative allosteric modulators of the $\mathrm{g}$ aminobutyric acid $A$ (GABA-A) receptor, such as dehydroepiandrostenedione (DHEA) and may influence the behavioral effects of drugs [34].

In a recent revision [35], estradiol level fluctuations are associated with sex differences in dopamine signaling in the mesolimbic reward system; in animal models, it has been demonstrated that striatal dopamine release is increased during phases of the cycle with high levels of estradiol [36]. Also, high levels of estradiol are related to increased responses to cocaine and cocaine-related cues [37]. This could explain that during phases with elevated estradiol concentrations, animals tended to self-administer more cocaine.

In human studies, alcohol use in women has been associated with increased levels of testosterone and estradiol [38]; studies showed contradictory results regarding progesterone, but one study performed taking into account the menstrual cycle concluded that alcohol use was associated with higher progesterone levels during the luteal phase [38].

In the case of psychostimulants, during the follicular phase of the menstrual cycle, in which estradiol levels are high and progesterone low, greatest responsivity to stimulants has been found [39]; in response to cocaine administration, women in the luteal phase reported lower ratings of feeling high than women in the follicular phase or men [39]. On the other hand, progesterone has been associated with an attenuation of the subjective response to smoked cocaine in women, but not men [40], and has been proposed as a treatment for psychostimulant addiction; and there are some studies with promising results with progesterone for the treatment of cocaine addiction [41] and nicotine addiction [42] in post-partum women. Although small significant differences, both studies showed more risk for relapse in women in the placebo group.

Studies of nicotine show a potential greater saliency in the luteal phase of the cycle, and women quitting during the luteal phase reported significantly greater increases in tobacco withdrawal and self-reported depressive symptoms than women quitting during the follicular phase [43, 44].

\section{Glutamate System}

The glutamate system is a key regulator of addiction-related behaviors. A recent review describes different sex-responses in the glutamate system [45]. First, men have higher brain concentrations of glutamate in the prefrontal cortex [46], but in the cerebellum and the striatum, the concentrations are higher in women [47]. The levels of glutamate and glutamate receptor expression are also variable through the menstrual 
cycle, probably due to a regulation of the glutamate system by sexual hormones.

Also, glutamate receptor expression varies between men and women, and also, in animal models, there are variations between males and females during the menstrual cycle [45]. Other differences described in the glutamate system are as follows: in nucleus accumbens, the metabotropic glutamate receptor 5 (mGluR5) mediates estradiol-induced spine density alterations; this could explain a reduction in cocaine and alcohol-seeking behavior in rats [48]. Differences in expression in some receptor subunits, for example, the NR1 subunit of the $N$-methyl-D-aspartate (NMDA) receptor a major glutamate receptor subtype; NR1 expression is increased in the amygdala of females, which in turn, it has been also related to cue-induced reinstatement [49]. Variations at this level explain differences in the response to strategies to reduce drugseeking between men and women. As described before, females are more vulnerable to stress-induced relapse, and this could be mediated by a greater resilience to NMDA and aminomethylphosphonic acid (AMPA) receptor subunit alterations following chronic stress [50]. Finally, differences have been described in the system xc-. The system $\mathrm{xc}^{-}$- is a transmembrane sodium-independent and chloride-dependent antiporter of cystine and glutamate, that exchanges extracellular cystine for intracellular glutamate. The system $\mathrm{xc}-$ can regulate the antioxidant capacity of cells and, in some regions, is the major source of extracellular glutamate [51]. In this regard, the system xc- appears to regulate glutamate levels in the nucleus accumbens in males, but not in females; this could explain inconsistent results in pharmacological trials, for example, in the case of $N$-acetylcysteine [52].

\section{Sex Differences in Stress Reactivity and Relapse to Substance Abuse}

Sex differences in neuroendocrine adaptations to stress and reward systems may mediate women's susceptibility to drug abuse and relapse [53]. Several studies have examined sex differences in stress response (e.g., subjective, autonomic) and relapse [53, 54].

Among substance-dependent subjects, the attenuated neuroendocrine stress response in women (i.e., blunted adrenocorticotropic hormone and cortisol) has been shown following exposure to stress and drug cues [55]. This hypothalamicpituitary-adrenocortical (HPA) dysregulation in women may be one key to enhanced vulnerability to relapse in response to negative affect, as it may be associated with greater emotional intensity at lower levels of HPA arousal [56].

\section{Cannabinoid System}

Several sexual differences have been found in the endocannabinoid system (ECS). Whereas animal studies are quite consistent in showing higher brain cannabinoid receptor type 1 (CB1) density in males than in females, human in vivo studies of sex differences have yielded discrepant findings. One study using positron emission tomography (PET) and a high-affinity, subtype-selective radioligand, the fluorine-18labeled PET radiotracer ([(18)F]MK-9470), showed that CB1 binding was higher in healthy males than in females in all the brain areas investigated. Moreover, they found that CB1 binding increased with aging in females which may suggest an influence of changing levels of sex hormones in this sex [57]. Other human imaging studies have reported greater brain CB1 receptor availability in healthy females than in men [58]. Although there is scarce research in that aspect, in general, animal studies support behavioral alterations reported in humans and have revealed diverse sex differences and potential underlying mechanisms: altered mesolimbic dopaminergic and hippocampal glutamatergic systems and interference with prefrontal cortex maturation [59••].

\section{Genetic Basis of Sex Differences}

Heritability of SUD has been previously described [60] through family, adoption, and twin studies. The heritability of SUDs is variable depending on the substance, from 0.39 for hallucinogens to 0.72 for cocaine [57]. The heritability has been evaluated in a few studies with contradictory results [61]. Limited sample sizes difficult the comparison between sexes in the studies [62].

In the case of alcohol, recent studies pointed out social factors that are more involved in the development of the disorder than sex genetic influences $[63,64]$. In the case of a cocaine use disorder, the heritability seems to be lower for women than for men [65].

Few genome-wide association studies (GWAS) have been performed taking into account sex differences [62]. From these studies, some markers have been detected that modified the risk for substance use disorders in both women and men. For example, the nuclear transcription factor PBX/Knotted 1 Homeobox 2 (PKNOX2) could be a candidate gene for substance dependence in European-origin women and a variant at adhesion G-protein-coupled receptor V1 (ADGRV1) gene was associated with opioid addiction in African American males [66].

\section{Environmental Factors: the Role of Intimate Partner Violence}

Women with SUD are more likely than men to come from families with other addicted members (genetic predisposition, family history, or environmental stress) and have experienced more disruption in their families. Also, they usually are engaged in relationships with substance-abusing partners who initiate women in drug use and sometimes are forced to use 
drugs with the partner. Addicted partners also support their drug use through prostitution, and they suffer a higher prevalence of intimate partner violence [59*0]. As described previously, there is an excess of psychiatric comorbidity in women exposed to intimate partner violence and SUD [59••].

Other sex/gender-specific medical problems to mention, related to drug use, are infertility, abortion, vaginal infections, and premature delivery. All of those affecting directly women's physical and mental health.

On the social side, it is known that women are more likely to come from formally disrupted families (environmental stress) with other addicted members (genetic predisposal), as well as dating a drug-abuser partner and eventually trading drug-use through prostitution, increasing considerably the vulnerability to acquire infections like human immunodeficiency virus (HIV) and hepatitis C (HCV). According to the $\mathrm{WHO}$, it is estimated that the prevalence rates of lifetime Intimate Partner Violence (IPV) in women undergoing SUD range between 40 and $70 \%$ compared to $17-35 \%$ in the general population [67]. There is a bidirectional relationship between alcohol use disorder and exposure to physical or sexual IPV and drug use also increases odds of IPV victimization [68]; there are three times greater odds of IPV perpetration in couples who use drugs [69].

Many other obstacles that women have to overcome before entering treatment must also be taken into account: the assumption of motherhood and associated morality, feelings of guilt, social stigma, pregnancy in the context of substance use, and lack of support from family members [70].

\section{Clinical Features}

Women entering substance abuse treatment programs present a more severe clinical profile attending to social, medical, psychological, and psychiatric comorbidities. Despite having used less of the substance and for a shorter period of time (later onset), the escalation of severity and decline in functionality is more rapid (telescoping effect, described before).

When analyzing the subjective effects of drugs, sex could be a modulating factor in mental and addictive disorders [71], but results are controversial, with some studies showing no differences between men and women, others describing more subjective effects in men whereas others showed greater effects in women [16••].

Women may be more susceptible to craving and relapse, which are key phases of the addiction cycle and show greater physiological withdrawal symptoms [29, 72], and greater userelated effects [73] than men. For both males and females, SUD is associated with an increased risk of at least one other mental health condition. However, women experience higher rates of comorbid depression and anxiety, while men experience more comorbid antisocial personality disorder [73-75].
Also, men and women experiment with a different profile of withdrawal symptoms under detoxification [76]. And women with alcohol use disorder are known to become intoxicated with smaller quantities of alcohol, achieving higher blood concentrations than men and show a lower tolerance even with an equal alcohol blood level [25]. This brings up the theory that ovarian steroid hormones may influence the behavioral effect of drugs [34]. Also, women exhibit greater withdrawal response with abstinence compared to men and tend to exhibit relapse due to cue-induced craving more than men suggesting that there might be sex differences in stress reactivity and relapse to drug use [55].

In the case of women with cocaine use disorder, they take less time to become addicted and report less euphoria and dysphoria than men [77].

In the case of nicotine, women and men are equally likely to become addicted to nicotine, yet women typically smoke cigarettes with lower nicotine content than those smoked by men, smoke fewer cigarettes per day, and inhale less deeply than men [78]. Females report positive mood increases to a greater extent after nicotine smoking and show a great decline in a positive mood during smoking abstinence than men.

\section{Psychiatric Comorbidity (Dual Diagnosis)}

There is a great amount of research showing that women presented more comorbid psychiatric disorders than men and also, more comorbidity than expected in women without SUD [12, 79] and these disorders are associated with substance-use problems. This risk increased if women had experienced intimate partner violence [59••]. The presence of comorbid psychiatric disorders, such as depression and anxiety, ends in a more severe course of both diseases, with more severity of symptoms (SUD and affective disorder), more suicide attempts and more admissions to psychiatric wards [80, 81].

Depressive symptoms should be taken into account in the evolution of women who suffer from a substance use disorder because it could be related to the result of a treatment since it could be associated with craving and relapse into alcohol consumption $[82,83]$. On the other hand, the greater the severity of the depressive episode, the lower the compliance with the treatment [84] and the lower the response rate to it [85]. Given the elevated trauma exposure suffered among women who used rugs, the presence of comorbid posttraumatic stress disorder (PTSD) is high, mainly related to the experience of intimate partner violence victimization, sexual assault, and childhood abuse. In this sense, the study by Tirado-Muñoz et al. (2018), concluded that psychiatric comorbidities among women who inject drugs are common as they showed higher rates of PTSD, depression, and anxiety, increasing the proportions of dual disorders in women suffering from SUD; those women who inject drugs reporting IPV victimization (70\%) 
were almost two times likely to meet criteria for PTSD (OR $1.9595 \%$ CI 1.10-3.48) [59••].

\section{Other (Medical) Comorbidity}

Women who abuse drugs have been found to get sicker more quickly and suffer higher rates of liver problems, hypertension, diabetes, anemia, and gastrointestinal disorders than men. Women also experience sex-specific medical problems as a result of their addiction, such as a higher risk for infertility, vaginal infections, repeat miscarriages, and premature delivery $[16 \bullet \cdot$. Also, women are more vulnerable than men to infection with HIV and HCV: more likely to use drugs with many partners, exchange sex for money or drugs, share paraphernalia with an injection partner and have difficulty negotiating condom use with their intimate partners, especially when experiencing intimate partner violence victimization.

\section{Alcohol}

The somatic and family consequences derived from the use of alcohol have a greater incidence in women; while legal, labor, and social problems are more prevalent in men [86]. Despite lower levels of alcohol intake and shorter periods of drinking, women suffer more severe medical consequences, including liver cirrhosis $[12,87]$. The medical comorbidity appears after a shorter duration of alcohol use and with lower quantities, compared to men [88]. Postmenopausal women who drink moderate to heavy amounts of alcohol also have other health problems, including breast cancer. They are at higher risk for breast cancer and heart disease even if the amount they drink is less than that of their male counterparts [12••]; the underlying mechanism could be the increase in the levels of testosterone and estrogen induced by alcohol [89]. Other problems associated have been a decreased fertility [90] and more risk of spontaneous abortion [91]. Also, neurological effects are more severe and prevalent in alcohol-addicted women than in men, and cognitive impairment appears more prematurely [92].

Finally, women who chronically abuse alcohol have death rates 50 to $100 \%$ higher than men who have the same alcohol use patterns. On the other side, the risk of death increases in women with 2-3 standard drinks by day, whereas in men increases with 4 standard drinks [93].

\section{Nicotine}

Women may be at even greater risk than men for smokingrelated diseases, including lung cancer and myocardial infarction [94]. Men have higher prevalence rates of chronic obstructive pulmonary disease than women, which has been attributed to the historically higher rates of cigarette smoking. However, the increased rates of cigarette smoking in women within the past several decades have been associated with steadily increasing rates of chronic obstructive pulmonary disease in women. Exposure to environmental tobacco smoke may be associated with an increased risk for breast cancer [79].

\section{Treatment}

\section{Accessibility}

Treatment access is difficult for patients with addictive disorders due to systemic, structural, and a personal-level barrier to a different system, including staff regards and user barriers $[79,95]$. Addiction stigma is an important barrier to access treatment that could exacerbate the structural and individual barriers [96]. Moreover, women with SUD suffer more negative attitudes than men, receive more denigrating adjectives and experience more perceived stigma [97-99].

In general, women tend to search less for treatment than men [100]. Women face many factors that can limit their access as follows: to child care: they have to be available, affordable childcare, greater concerns about issues related to children compared with men; issues related to pregnancy (lack of services for pregnant women, fear of losing custody when the baby is born, fear of prosecution); resistance or hostility from family members; dealing with a relationship with a drugabusing partner; greater exposure to physical and sexual abuse (IPV) and inadequate health insurance; poor social support; and poverty (difficulty with transportation to treatment sites), psychiatric comorbidity, and the lack of gender-responsive protocols and treatments/interventions.

\section{Treatment Response}

Although women are less likely to receive specialized treatment for SUD, they performed better in the case of alcohol use disorders [101]. The time until relapse has been described as similar for both genders, but women take longer to relapse in heavy drinking. The reasons for relapse in alcohol use are different for men and women; women tend to relapse to cope with negative affect, whereas men relapse due to social pressure to drink [12••]. No clear differences have been described in terms of pharmacological response in alcohol treatments (naltrexone and acamprosate). Also, in the case of prescription opioid addiction, no differences in terms of response have been described [15].

In the case of nicotine addiction, the response is clearly worse for women [102], except for varenicline, which some studies showed some more benefits of this treatment in women [103, 104].

In the case of psychological treatments, studies showed similar outcomes for men and women for cognitivebehavioral therapy and contingency management [105-107]. Treatment retention has not been shown differences in men and women [108]. 


\section{Social Consequences}

As in the case of medical and psychiatric comorbidity, also, social consequences are more severe for women than for men. Women experience more stigma than men [109]; substance use has been more disapproved for women than for men, mainly in some cultures, as Latin [110]. The social consequences of addiction in women are more relevant in the family, for example, with higher rates of divorce compared to addicted men [111].

In the case of studies and occupation, the context of substance use is different between men and women. Men with a low socioeconomic or educational level are more likely to suffer alcohol abuse, and the opposite occurs in women: the higher education or socioeconomic status, the greater the possibility of alcohol abuse [112]. In longitudinal studies performed to analyze the relationship between alcohol use and stress at work, the results showed an association between the degree of stress and risky alcohol consumption, being more relevant in men than in women [113]; what differentiates genders is the type of work: physical high exigency work is associated with binge drinking in men, whereas women in management tasks drink with more frequency but with less intensity [114].

Another important aspect is that women reported more gender-related abusive experiences during training, and these women were more likely to be problem drinkers; the possible explanation could be the use of alcohol to cope with traumatic experiences [115]. On the other hand, legal problems are more prevalent in men than in women [116].

\section{Conclusions}

The most relevant data is that there is an increasing substance use in females, and the gender gap may be narrowing. Reasons for drug initiation and use are different for men and women. Women present a rapid progression from drug use to addiction. Females suffer from severe consequences of drug use: pregnancy complications and more severe medical problems. Also, psychiatric comorbidity, mainly depression and PTSD are more frequent in females than in males. This psychiatric comorbidity increases the risk of HCV and HIV infections among women who use drugs. Treatment response is also different for women and men; women experiment more craving and present a greater risk for relapse. These differences could be explained in part by biological differences between both sexes associated with sex hormones. At the social level, women experience more stigma, and a high prevalence of intimate partner violence has been consistently described among women with SUD, which in turn, led to more risk for psychiatric comorbidity. On the other hand, specific research in women who use drugs is very scarce and treatments are not gender oriented.

Thus, women are at greater risk for a range of medical, psychiatric, and psychosocial consequences that must be considered when identifying pharmacological and/or behavioral interventional strategies females may benefit greatly, and that may differ from those most beneficial for men. For these reasons, it is important to guarantee access to the appropriate treatment of females who use substances and a need for a gender perspective in the treatment and research of substance use disorders.

Authors' Contributions JMP and MAF performed the references' search; FF and MR wrote the initial draft of the manuscript; AMC, JTM, and MT provided the critical revision of the manuscript for key intellectual content. The authors reviewed and approved the final manuscript.

Funding This work was supported by grants from the Instituto de Salud Carlos III-ISCIII (FIS-FEDER, P2018I030, and Red de Trastornos Adictivos 2016 (RD16/0017/0010) and Suport Grups de Recerca AGAUR-Gencat (2017 SGR 530). The funding agencies had no role in study design, data collection, interpretation, or influence on writing.

\section{Compliance with Ethical Standards}

Conflicts of Interest FF has received during the last 3 years of travel grants from Lundbeck, Otsuka, Indivior, Pfizer, Gilead, and Servier, and she has received grant/research support from Indivior and Servier. MR has been a consultant/advisor and/or speaker for Lundbeck and Servier. MT has been a consultant/advisor and/or speaker for Gilead Sciences, Merck Sharp \& Dohme Corp, Indivior, Mundipharma Pharmaceutics, Servier Adamed, Lundbeck, and Rovi.

The authors declare no conflict of interest, and the funders had no role in the design of the study, data collection, analyses, and interpretation, in the writing of the manuscript, or in the decision to publish the results.

Ethics Approval Not applicable.

\section{References}

Papers of particular interest, published recently, have been highlighted as:

- Of importance

•- Of major importance

1. World Drug Report. (2020). (United Nations publication, Sales No. E.20.XI.6).

2. National Institutes of Health, O. o. R. o. W. s. H. (n.d.). Sex/ Gender. Retrieved August 17, 2020, from https://orwh.od.nih. gov/research/sex-gender/.

3. Magar V, Heidari S, Zamora F, Coates A, Simelela PN, Swaminathan S. Gender mainstreaming within WHO: not without equity and human rights. Lancet. 2019;393(10182):1678-9. https://doi.org/10.1016/S0140-6736(19)30763-9.

4. WHO. Thirteenth general programme of work, 2019-2023 report by the Director-General. Geneva: World Health Organization, 2018. 
5. Jackson A, Shannon L. Barriers to receiving substance abuse treatment among rural pregnant women in Kentucky. Matern Child Health J. 2012;6:1762-70. https://doi.org/10.1007/s10995-0110923-5.

6. Small J, Curran GM, Booth B. Barriers and facilitators for alcohol treatment for women: are there more or less for rural women? J Subst Abus Treat. 2010;39:1-13. https://doi.org/10.1016/j.jsat. 2010.03.002.

7. Cousins S. COVID-19 has "devastating" effect on women and girls. Lancet. 2020;396(10247):301-2. Published online 2020 Jul 30. https://doi.org/10.1016/S0140-6736(20)31679-2.

8. Liu N, Zhang F, Wei C, Jia Y, Shang Z, Sun L, et al. Prevalence and predictors of PTSS during COVID-19 outbreak in China hardest-hit areas: gender differences matter. Psychiatry Res. 2020;287:112921. Published online 2020 Mar 16. https://doi. org/10.1016/j.psychres.2020.112921.

9. Regier DA, Farmer ME, Rae DS, Locke BZ, Keith SJ, Judd LL, et al. Comorbidity of mental disorders with alcohol and other drug abuse. Results from the Epidemiologic Catchment Area (ECA) Study. JAMA. 1990;264(19):2511-8.

10. Compton WM, Thomas YF, Stinson FS, Grant BF. Prevalence, correlates, disability, and comorbidity of DSM-IV drug abuse and dependence in the United States: results from the national epidemiologic survey on alcohol and related conditions. Arch Gen Psychiatry. 2007;64(5):566-76. https://doi.org/10.1001/archpsyc. 64.5.566.

11. Rehm J, Shield KD. Global burden of disease and the impact of mental and addictive disorders. Curr Psychiatry Rep. 2019;21(2): 10. https://doi.org/10.1007/s11920-019-0997-0

12.• Erol A, Karpyak VM. Sex and gender-related differences in alcohol use and its consequences: contemporary knowledge and future research considerations. Drug Alcohol Depend. 2015;156:1-13. https://doi.org/10.1016/j.drugalcdep.2015.08.023 This is a very interesting review of the evidence of sex and gender differences in alcohol use and its consequences.

13. Ait-Daoud N, Blevins D, Khanna S, Sharma S, Holstege CP. Women and addiction. Psychiatr Clin North Am. 2017;40:28597. https://doi.org/10.1016/j.psc.2017.01.005.

14. Marsh JC, Park K, Lin YA, Bersamira C. Gender differences in trends for heroin use and nonmedical prescription opioid use, 2007-2014. J Subst Abus Treat. 2018;87:79-85.

15. McHugh RK, Devito EE, Dodd D, Carroll KM, Potter JS, Greenfield SF, et al. Gender differences in a clinical trial for prescription opioid dependence. J Subst Abus Treat. 2013;45(1):3843. https://doi.org/10.1016/j.jsat.2012.12.007.

16.•• McHugh RK, Votaw VR, Sugarman DE, Greenfield SF. Sex and gender differences in substance use disorders. Psychol Rev. 2018;66:12-23. https://doi.org/10.1016/j.cpr.2017.10.012 A comprehensive review of main differences in addiction between men and women.

17. Brady KT, Randall CL. Gender differences in substance use disorders. Psychiatry Clin North Am. 1999;22:241-52. https://doi. org/10.1016/S0193-953X(05)70074-5.

18. Greenfield SF, Back SE, Lawson K, Brady KT. Substance abuse in women. Psychiatry Clin North Am. 2010a;33:339-55. https:// doi.org/10.1016/j.psc.2010.01.004.

19. Keyes KM, Martins SS, Blanco C, Hasin DS. Telescoping and gender differences in alcohol dependence: new evidence from two national surveys. Am J Psychiatry. 2010;167(8):969-76. https:// doi.org/10.1176/appi.ajp.2009.09081161.

20. Johnson PB, Richter L, Kleber HD, McLellan AT, Carise D. Telescoping of drinking-related behaviors: gender, racial/ethnic, and age comparisons. Subst Use Misuse. 2005;40(8):1139-51. https://doi.org/10.1081/ja-200042281.
21. Kuntsche E, Muller S. Why do young people start drinking? Motives for first-time alcohol consumption and links to risky drinking in early adolescence. Eur Addict Res. 2012;18:34-9.

22. Haas AL, Peters RH. Development of substance abuse problems among drug involved offenders. Evid Telesc Eff J Subst Abus. 2000;12:241-53.

23. Wilson HW, Widom CS. A prospective examination of the path from child abuse and neglect to illicit drug use in middle adulthood: the potential mediating role of four risk factors. J Youth Adolesc. 2009;38:340-54.

24. Bravo F, Gual A, Lligoña A, Colom J. Gender differences in the long-term outcome of alcohol dependence treatments: an analysis of twenty-year prospective follow up. Drug Alcohol Rev. 2013;32:381-8. https://doi.org/10.1111/dar.12023.

25. Calafat A, Fernández-Hermida JR, Becoña E, Juan M, Duch M, Fernández del Rio E, et al. Blood alcohol level tests in nightlife recreational settings as a preventive tool. Actas Esp Psiquiatr. 2013;41:10-6.

26.• Becker JB, Chartoff E. Sex differences in neural mechanisms mediating reward and addiction. Neuropsychopharmacology. 2019;44(1):166-83. https://doi.org/10.1038/s41386-018-0125-6 Interesting review about neurobiological mechanisms underlying addictive disorders and its differences between men and women.

27.• Koob GF, Volkow ND. Neurobiology of addiction: a neurocircuitry analysis. Lancet Psychiatry. 2016;3(8):760-73. https://doi.org/10.1016/S2215-0366(16)00104-8 Important review about neurobiological mechanisms underlying addictive disorders.

28. Ward RJ, Coutelle C. Women and alcohol susceptibility: could differencesin alcohol metabolism predispose women to alcoholrelated diseases? Arch Womens Mental Health. 2003;6:231-8.

29. Becker JB, Koob GF. Sex differences in animal models: focus on addiction. Pharmacol Rev. 2016;68:242-63. https://doi.org/10. 1124/pr.115.011163.

30. Sanchis-Segura C, Becker JB. Why we should consider sex (and study sex differences) in addiction research. Addict Biol. 2016;21(5):995-1006. https://doi.org/10.1111/adb.12382.

31. Benowitz NL, Lessov-Schlaggar CN, Swan GE, Jacob P. Female sex and oral contraceptive use accelerate nicotine metabolism. Clin Pharmacol Ther. 2009;79:480-8. https://doi.org/10.1016/j. clpt.2006.01.008.

32. Lukas SE, Sholar M, Lundahl LH, Lamas X, Kouri E, Wines JD, et al. Sex differences in plasma cocaine levels and subjective effects after acute cocaine administration in human volunteers. Psychopharmacology. 1996;125(4):346-54.

33. Mendelson JH, Mello NK, Sholar MB, Siegel AJ, Kaufman MJ, Levin JM, et al. Cocaine pharmacokinetics in men and in women during the follicular and luteal phases of the menstrual cycle. Neuropsychopharmacol. 1999;21:294-303. https://doi.org/10. 1016/S0893-133X(99)00020-2.

34. Newman JL, Mello NK. Neuroactive gonadal steroid hormones and drug addiction in women. In: Brady KT, Back SE, Greenfield SF, editors. Women and addiction: a comprehensive handbook. New York: Guilford Press; 2009. p. 35-64.

35. Kokane SS, Perrotti LI. Sex differences and the role of estradiol in mesolimbic reward circuits and vulnerability to cocaine and opiate addiction. Front Behav Neurosci. 2020;14:74. https://doi.org/10. 3389/fnbeh.2020.00074 eCollection 2020.

36. Yoest KE, Quigley JA, Becker JB. Rapid effects of ovarian hormones in dorsal striatum and nucleus accumbens. Horm Behav. 2018;104:119-29. https://doi.org/10.1016/j.yhbeh.2018.04.002.

37. Calipari ES, Juarez B, Morel C, Walker DM, Cahill ME, Ribeiro E, et al. Dopaminergic dynamics underlying sex-specific cocaine reward. Nat Commun. 2017;8:13877. 
38. Garcia-Closas M, Herbstman J, Schiffman M, Glass A, Dorgan JF. Relationship between serum hormone concentrations, reproductive history, alcohol consumption and genetic polymorphisms in pre-menopausal women. Int J Cancer. 2012;102:172-8. https:// doi.org/10.1002/ijc.10651.

39. Sofuoglu M, Dudish-Poulsen S, Nelson D, Pentel PR, Hatsukami DK. Sex and menstrual cycle differences in the subjective effects from smoked cocaine in humans. Exp Clin Psychopharmacol. 1999;7(3):274-83. https://doi.org/10.1037//1064-1297.7.3.274.

40. Evans SM, Foltin RW. Exogenous progesterone attenuates the subjective effects of smoked cocaine in women, but not in men. Neuropsychopharmacology. 2006;31:659-74.

41. Yonkers KA, Forray A, Nich C, Carroll KM, Hine C, Merry BC, et al. Progesterone reduces cocaine use in postpartum women with a cocaine use disorder: a randomized, double-blind study. Lancet Psychiatry. 2014;1(5):360-7. https://doi.org/10.1016/S22150366(14)70333-5.

42. Forray A, Gilstad-Hayden K, Suppies C, Bogen D, Sofuoglu M, Yonkers KA. Progesterone for smoking relapse prevention following delivery: a pilot, randomized, double-blind study. Psychoneuroendocrinol. 2017;86:96-103. https://doi.org/10. 1016/j.psyneuen.2017.09.012.

43. Carpenter MJ, Upadhyaya HP, LaRowe SD, Saladin ME, Brady KT. Menstrual cycle phase effects on nicotine withdrawal and cigarette craving: a review. Nicotine Tob Res. 2006;8(5):62738. https://doi.org/10.1080/14622200600910793.

44. Weinberger AH, Smith PH, Allen SS, Cosgrove KP, Saladin ME, Gray KM, et al. Systematic and meta-analytic review of research examining the impact of menstrual cycle phase and ovarian hormones on smoking and cessation. Nicotine Tob Res. 2015;17(4): 407-21. https://doi.org/10.1093/ntr/ntu249.

45. Giacometti LL, Barker JM. Sex differences in the glutamate system: implications for addiction. Neurosci Biobehav Rev. 2020;113:157-68. https://doi.org/10.1016/j.neubiorev.2020.03. 010 .

46. O'Gorman RL, Michels L, Edden RA, Murdoch JB, Martin E. In vivo detection of GABA and glutamate with MEGA-PRESS: reproducibility and gender effects. J Magn Reson Imaging. 2011;33:1262-7. https://doi.org/10.1002/jmri.22520.

47. Zahr NM, Mayer D, Rohlfing T, Chanraud S, Gu M, Sullivan EV, et al. In vivo glutamate measured with magnetic resonance spectroscopy: behavioral correlates in aging Neurobiol. Aging. 2013;34:1265-76. https://doi.org/10.1016/j.neurobiolaging.2012. 09.014 .

48. Peterson BM, Mermelstein PG, Meisel RL. Estradiol mediates dendritic spine plasticity in the nucleus accumbens core through activation of mGluR5. Brain Struct Funct. 2015;220:2415-22. https://doi.org/10.1007/s00429-014-0794-9.

49. Wang Y, Ma Y, Hu J, Cheng W, Jiang H, Zhang X, et al. Prenatal chronic mild stress induces depression-like behavior and sexspecific changes in regional glutamate receptor expression patterns in adult rats. Neuroscience. 2015;301:363-74. https://doi. org/10.1016/j.neuroscience.2015.06.008.

50. Bertholomey ML, Nagarajan V, Torregrossa MM. Sex differences in reinstatement of alcohol seeking in response to cues and yohimbine in rats with and without a history of adolescent corticosterone exposure. Psychopharmacology. 2016;233:2277-87. https://doi. org/10.1007/s00213-016-4278-x.

51. Massie A, Boillée S, Hewett S, Knackstedt L, Lewerenz J. Main path and byways: non-vesicular glutamate release by system xc(-) as an important modifier of glutamatergic neurotransmission. J Neurochem. 2015;135(6):1062-79. https://doi.org/10.1111/jnc. 13348.

52. Goenaga J, Powell GL, Leyrer-Jackson JM, Piña J, Phan S, Prakapenka AV, et al. N-acetylcysteine yields sex-specific efficacy for cue-induced reinstatement of nicotine seeking. Addict Biol. 2020;25(1):e12711. https://doi.org/10.1111/adb. 12711.

53. Sinha R. How does stress increase risk of drug abuse and relapse? Psychopharmacology. 2001;158(4):343-59. https://doi.org/10. 1007/s002130100917.

54. Sinha R. The role of stress in addiction relapse. Curr Psychiatry Rep. 2007;9(5):388-95. https://doi.org/10.1007/s11920-0070050-6.

55. Back SE, Waldrop AE, Saladin ME, Yeatts SD, Simpson A, McRae AL, et al. Effects of gender and cigarette smoking on reactivity to psychological and pharmacological stress provocation. Psychoneuroendocrinology. 2008;33(5):560-8. https://doi. org/10.1016/j.psyneuen.2008.01.012.

56. Fox HC, Hong KA, Paliwal P, Morgan PT, Sinha R. Altered levels of sex and stress steroid hormones assessed daily over a 28-day cycle in early abstinent cocaine-dependent females. Psychopharmacol. 2008;195(4):527-36. https://doi.org/10.1007/ s00213-007-0936-3.

57. Van Laere K, Goffin K, Casteels C, Dupont P, Mortelmans L, de Hoon J, et al. Gender-dependent increases with healthy aging of the human cerebral cannabinoid-type 1 receptor binding using [18F]MK-9470 PET. Neuroimage. 2008;39:1533-41. https://doi. org/10.1016/j.neuroimage.2007.10.053.

58. Normandin MD, Zheng MQ, Lin KS, Mason NS, Lin SF, Ropchan J, et al. Imaging the cannabinoid CB1 receptor in humans with [11C] OMAR: assessment of kinetic analysis methods, test-retest reproducibility, and gender differences. J Cereb Blood Flow Metab. 2015;5:1313-22. https://doi.org/10. 1038/jcbfm.2015.46.

59.• Tirado-Muñoz J, Gilchrist G, Fischer G, Taylor A, Moskalewicz J, Giammarchi C, et al. Psychiatric comorbidity and intimate partner violence among women who inject drugs in Europe: a crosssectional study. Arch Women's Mental Health. 2018;21(3):259 69. https://doi.org/10.1007/s00737-017-0800-3 This study remarks the psychiatric and medical consequences of intimate partner violence among women who inject drugs.

60. Kendler KS, Myers J, Prescott CA. Specificity of genetic and environmental risk factors for symptoms of Cannabis, cocaine, alcohol, caffeine, and nicotine dependence. Arch Gen Psychiatry. 2007;64(11):1313-20.

61. Salvatore JE, Cho SB, Dick DM. Genes, environments, and sex differences in alcohol research. J Stud Alcohol Drugs. 2017;78(4): 494-501. https://doi.org/10.15288/jsad.2017.78.494.

62. Datta U, Schoenrock SE, Bubier JA, Bogue MA, Jentsch JD, Logan RW, et al. Prospects for finding the mechanisms of sex differences in addiction with human and model organism genetic analysis. Genes Brain Behav. 2020;19(3):e12645. https://doi.org/ 10.1111/gbb.12645.

63. Sudhinaraset M, Wigglesworth C, Takeuchi DT. Social and cultural contexts of alcohol use: influences in a social-ecological framework. Alcohol Res. 2016;38(1):35-45.

64. Verhulst B, Neale MC, Kendler KS. The heritability of alcohol use disorders: a meta-analysis of twin and adoption studies. Psychol Med. 2015;45(5):1061-72.

65. Van den Bree MBM, Johnson EO, Neale MC, Pickens RW. Genetic and environmental influences on drug use and abuse/ dependence in male and female twins. Drug Alcohol Depend. 1998;52(3):231-41.

66. Yang B-Z, Zhou H, Cheng Z, et al. Genomewide gene-by-sex interaction scans identify ADGRV1 for sex differences in opioid dependent African Americans. Sci Rep. 2019;9(1):1-9.

67. WHO https://apps.who.int/adolescent/second-decade/section/ section_4/level4_4.php

68. Devries KM, Child JC, Bacchus LJ, Mak J, Falder G, Graham K, et al. Intimate partner violence victimization and alcohol 
consumption in women: a systematic review and meta-analysis. Addiction. 2014;109:379-91.

69. Moore TM, Stuart GL, Meehan JC, Rhatigan DL, Hellmuth JC, Keen SM. Drug abuse and aggression between intimate partners: a meta-analytic review. Clin Psychol Rev. 2008;28:247-74.

70. Gilchrist G, Blázquez A, Torrens M. Exploring the relationship between intimate partner violence, childhood abuse and psychiatric disorders among female drug users in Barcelona. Adv Dual Diagn. 2012;5(2):46-58. https://doi.org/10.1108/ 17570971211241895.

71. Zagni E, Simoni L, Colombo D. Sex and gender differences in central nervous system-related disorders. Neurosci J. 2016;2016: 2827090. https://doi.org/10.1155/2016/2827090.

72. Copersino ML, Boyd SJ, Tashkin DP, Huestis MA, Heishman SJ, Dermand JC, et al. Sociodemographic characteristics of cannabis smokers and the experience of cannabis withdrawal. Am J Drug Alcohol Abuse. 2020;36:311-9. https://doi.org/10.3109/ 00952990.2010 .503825 .

73. Cooper ZD, Haney M. Investigation of sex-dependent effects of cannabis in daily cannabis smokers. Drug Alcohol Depend. 2014;136:85-91. https://doi.org/10.1016/j.drugalcdep.2013.12. 013

74. Colon-Perez LM, Pino JA, Saha K, Pompilus M, Kaplitz S, Choudhury N, et al. Functional connectivity, behavioral and dopaminergic alterations 24 hours following acute exposure to synthetic bath salt drug methylenedioxypyrovalerone. Neuropharmacol. 2018;137:178-93. https://doi.org/10.1016/j. neuropharm.2018.04.031.

75. NIDA. (2020). Drug facts: substance use in women | National Institute on Drug Abuse (NIDA). DrugFacts.

76. Sanvisens A, Zuluaga P, Short A, Rubio G, Gual A, Torrens M, et al. CohRTA study*. Sex-specific associations of alcohol withdrawal in patients admitted for the treatment of alcohol use disorder. J Addict Med. 2020;4. https://doi.org/10.1097/ADM. 0000000000000704.

77. Becker JB, Hu M. Sex differences in drug abuse. Front Neuroendocrinol. 2008;29:36-47.

78. Shiffman S, Paton SM. Individual differences in smoking: gender and nicotine addiction. Nicotine Tob Res. 1999;1(2):S153-7; discussion S165-6. https://doi.org/10.1080/14622299050011991.

79. Taghizadeh N, Vonk JM, Boezen HM. Lifetime smoking history and cause-specific mortality in a cohort study with 43 years of follow-up. PLoS One. 2016;11(4):e0153310. https://doi.org/10. 1371/journal.pone.0153310 eCollection 2016.

80. Haro JM, Palacín C, Vilagut G, Martínez M, Bernal M, Luque I, et al. Prevalence of mental disorders and associated factors: results from the ESEMeD-Spain study. Med Clin (Barc). 2006;126(12): 445-51. https://doi.org/10.1157/13086324.

81. Torrens M, Gilchrist G, Domingo-Salvany A, psyCoBarcelona Group. Psychiatric comorbidity in illicit drug users: substanceinduced versus independent disorders. Drug Alcohol Depend. 2011;113(2-3):147-56. https://doi.org/10.1016/j.drugalcdep. 2010.07.013

82. Abulseoud OA, Karpyak VM, Schneekloth T, Hall-Flavin DK, Loukianova LL, Geske JR, et al. A retrospective study of gender differences in depressive symptoms and risk of relapse in patients with alcohol dependence. Am J Addict. 2013;22:437-42. https:// doi.org/10.1111/j.1521-0391.2013.12021.x.

83. Zilberman ML, Tavares H, Hodgins DC, El-Guebaly N. The impact of gender, depression, and personality on craving. J Addict Dis. 2007;26:79-84. https://doi.org/10.1300/J069v26n01_10.

84. Gjestad R, Franck J, Hagtvet KA, Haver B. Level and change in alcohol consumption, depression and dysfunctional attitudes among females treated for alcohol addiction. Alcohol. 2011;46: 292-300. https://doi.org/10.1093/alcalc/agr018.
85. Merrill JE, Reid AE, Carey MP, Carey KB. Gender and depression moderate response to brief motivational intervention for alcohol misuse among college students. J Consult Clin Psychol. 2014;82:984-92. https://doi.org/10.1037/a0037039.

86. Beckman LJ. Women alcoholics. A review of social and psychological studies. J Stud Alcohol. 1975;36:797-824.

87. Simpson RF, Hermon C, Liu B, Green J, Reeves GK, Beral V, et al. Alcohol drinking patterns and liver cirrhosis risk: analysis of the prospective UK Million Women Study. Lancet Public Health. 2019;4(1):e41-8. https://doi.org/10.1016/S2468-2667(18)302305 .

88. Bradley KA, Badrinath S, Bush K, Boyd-Wickizer J, Anawalt B. Medical risks for women who drink alcohol. Gen Intern Med. 1998;13(9):627-39. https://doi.org/10.1046/j.1525-1497.1998. cr187.x.

89. Gunter MJ, Lange T, Chlebowski RT, Lane D, Farhat GN, Freiberg MS, et al. Quantifying mediating effects of endogenous estrogen and insulin in the relation between obesity, alcohol consumption, and breast cancer. Cancer Epidemiol Biomark Prev. 2012;21:1203-12.

90. Eggert J, Theobald H, Engfeldt P. Effects of alcohol consumption on femalefertility during an 18-year period. Fertil Steril. 2004;81: 379-83. https://doi.org/10.1016/j.fertnstert.2003.06.018.

91. Chiodo LM, Bailey BA, Sokol RJ, Janisse J, Delaney-Black V, Hannigan JH. Recognized spontaneous abortion in midpregnancy and patterns of pregnancy alcohol use. Alcohol. 2012;46:261-7. https://doi.org/10.1016/j.alcohol.2011.11.006.

92. Lyu J, Lee SH. Alcohol consumption and cognitive impairment among Korean older adults: does gender matter? Int Psychogeriatr. 2014;26:335-40.

93. Holman CD, English DR, Milne E, Winter MG. Meta-analysis of alcohol and all-cause mortality: a validation of NHMRC recommendations. Med J Aust. 1996;164:141-5.

94. Mucha L, Stephenson J, Morandi N, Dirani R. Meta-analysis of disease risk associated with smoking, by gender and intensity of smoking. Gend Med. 2006;3(4):279-91. https://doi.org/10.1016/ s1550-8579(06)80216-0.

95. Gilchrist G, Fonseca F, Torrens M. Access to treatment for people with alcohol and other substance abuse problems. Adicciones. 2011a;23(4):343-8.

96. Volkow ND. It's time for addiction science to supersede stigma. $2008 \mathrm{https} / / / \mathrm{www}$. sciencenews.org/article/it\%E2\%80\%99s-timeaddiction-science-supersede-stigma Published October 24, 2008.

97. Spooner C, Saktiawati MA, Lazuardi E, Worth H, Subronto W, Padmawati RS. Impacts of stigma on HIV risk for women who inject drugs in Java: a qualitative study. Int J Drug Pol. 2015;26: 1244-50.

98. Terplan M, Kennedy-Hendricks A, Chislom MS. Prenatal substance use: exploring assumptions of maternal unfitness. Subst Abuse Res Treat. 2015;9:1-4.

99. Verissimo ADO, Grella CE. Influence of gender and race/ethnicity on perceived barriers to help seeking for alcohol or drug problems. J Subst Abus Treat. 2017;75:54-61. https:// doi.org/10.1016/j.jsat.2016.12.013.

100. Greenfield SF, Brooks AJ, Gordon SM, Green CA, Kropp F, McHugh RK, et al. Substance abuse treatment entry, retention, and outcome in women: a review of the literature. Drug Alcohol Depend. 2007;86(1):1-21. https://doi.org/10.1016/j.drugalcdep. 2006.05.012.

101. Greenfield SF, Pettinati HM, O’Malley S, Randall PK, Randall CL. Gender differences in alcohol treatment: an analysis of outcome from the COMBINE study. Alcohol Clin Exp Res. 2010b;34(10):1803-12. https://doi.org/10.1111/j.1530-0277. 2010.01267.x.

102. Smith PH, Kasza KA, Hyland A, Fong GT, Borland R, Brady K, et al. Gender differences in medication use and cigarette smoking 
cessation: results from the International Tobacco Control Four Country Survey. Nicotine Tob Res. 2015;17(4):463-72. https:// doi.org/10.1093/ntr/ntu212.

103. McKee SA, Smith PH, Kaufman M, Mazure CM, Weinberger AH. Sex differences in varenicline efficacy for smoking cessation: a meta-analysis. Nicotine Tob Res. 2016;18(5):1002-11. https:// doi.org/10.1093/ntr/ntv207.

104. Smith PH, Weinberger AH, Zhang J, Emme E, Mazure CM, McKee SA. Sex differences in smoking cessation pharmacotherapy comparative efficacy: a network meta-analysis. Nicotine Tob Res. 2017;19(3):273-81. https://doi.org/10.1093/ntr/ntw144.

105. Burch AE, Rash CJ, Petry NM. Sex effects in cocaine-using methadone patients randomized to contingency management interventions. Exp Clin Psychopharmacol. 2015;23(4):284-90. https://doi. org/10.1037/pha0000034.

106. Campbell AN, Nunes EV, Pavlicova M, Hatch-Maillette M, Hu MC, Bailey GL, et al. Gender-based outcomes and acceptability of a computer-assisted psychosocial intervention for substance use disorders. J Subst Abus Treat. 2015;53:9-15. https://doi.org/10. 1016/j.jsat.2014.12.006.

107. DeVito EE, Babuscio TA, Nich C, Ball SA, Carroll KM. Gender differences in clinical outcomes for cocaine dependence: randomized clinical trials of behavioral therapy and disulfiram. Drug Alcohol Depend. 2014;145:156-67. https://doi.org/10.1016/j. drugalcdep.2014.10.007.

108. Korte JE, Rosa CL, Wakim PG, Perl HI. Addiction treatment trials: how gender, race/ethnicity, and age relate to ongoing participation and retention in clinical trials. Subst Abus Rehabil. 2011;2:205-18. https://doi.org/10.2147/sar.s23796.

109. Melchior H, Hüsing P, Grundmann J, Lotzin A, Hiller P, Pan Y, et al. Substance abuse-related self-stigma in women with substance use disorder and comorbid posttraumatic stress disorder. Eur Addict Res. 2019;25(1):20-9. https://doi.org/10.1159/ 000496113.

110. Witbrodt J, Mulia N, Zemore SE, Kerr WC. Racial/ethnic disparities in alcohol-related problems: differences by gender and level of heavy drinking. Alcohol Clin Exp Res. 2014;38(6):1662-70. https://doi.org/10.1111/acer.12398.

111. Lex BW. Some gender differences in alcohol and polysubstance users. Health Psychol. 1991;10(2):121-32. https://doi.org/10. 1037//0278-6133.10.2.121.

112. Organización para la Cooperación y el Desarrollo Económicos (OECD). Tackling harmful alcohol use. Economics and Public Health Policy. París; OECD: 2015.

113. Siegrist J, Rödel A. Work stress and health risk behavior. Scand J Work Environ Health. 2006;32(6):473-81. https://doi.org/10 5271/sjweh.1052.

114. Barnes AJ, Zimmerman FJ. Associations of occupational attributes and excessive drinking. Soc Sci Med. 2013;92:35-42. https://doi.org/10.1016/j.socscimed.2013.05.023.

115. Richman JA, Rospenda KM. Gender roles and alcohol abuse. Costs of noncaring for future physicians. J Nerv Ment Dis. 1992t;180(10):619-26. https://doi.org/10.1097/00005053199210000-00002.

116. Westermeyer J, Boedicker AE. Course, severity, and treatment of substance abuse among women versus men. Am J Drug Alcohol Abuse. 2000;26(4):523-35.

Publisher's Note Springer Nature remains neutral with regard to jurisdictional claims in published maps and institutional affiliations. 